\title{
Clinical Stage III HPV-Mediated (p16- Positive) Oropharyngeal Carcinoma AJCC v8
}

National Cancer Institute

\section{Source}

National Cancer Institute. Clinical Stage III HPV-Mediated (p16-Positive) Oropharyngeal

Carcinoma AJCC v8. NCI Thesaurus. Code C132891.

Stage III includes: (T0, N3, M0); (T1, N3, M0); (T2, N3, M0); (T3, N3, MO); (T4, NO, M0); (T4, N1, M0); (T4, N2, M0); (T4, N3, M0). T0: No primary identified. T1: Tumor $2 \mathrm{~cm}$ or smaller in greatest dimension. T2: T umor larger than $2 \mathrm{~cm}$ but not larger than $4 \mathrm{~cm}$ in greatest dimension. T3: T umor larger than $4 \mathrm{~cm}$ in greatest dimension or extension to lingual surface of epiglottis. T4: T umor with moderately advanced local disease. Tumor invades the larynx, extrinsic muscle of tongue, medial pterygoid, hard palate, or mandible or beyond. Mucosal extension to lingual surface of epiglottis from primary tumors of the base of the tongue and vallecula does not constitute invasion of the larynx. N0: No regional lymph node metastasis. N1: Tumor with metastasis in one or more ipsilateral lymph nodes, none larger than $6 \mathrm{~cm}$. N2: T umor with contralateral or bilateral lymph nodes metastasis, none larger than $6 \mathrm{~cm}$. N3: Tumor with lymph node(s) metastasis, larger than $6 \mathrm{~cm}$. M0: No distant metastasis. (AJCC 8th ed.) 